\title{
Pretreatment of Coal Power Plant RO Retentate using AR Floc 100
}

\author{
E. Fosso-Kankeu*, L. Van Schalkwyk, J. Van Der Linde, G. Gericke and F.B. Waanders
}

\begin{abstract}
The water purification process at Eskom includes a reverse osmosis (RO) treatment plant. There are several limitations to this process depending on the water characteristics. The most common problems limiting the success of water purification include scaling, biological fouling and corrosion. This study is mainly focused on reducing scale forming agents in the RO system. Scaling is the precipitation of calcium and magnesium salts onto the equipment, primarily the RO membrane. These salts start to precipitate once the salt concentration in the water is higher than the allowable solubility constant. These salts can be removed from the water by a process called coagulation-flocculation. The success of such process is partly dependent on the type of flocculant and the dosage used. In this study the performances of one coagulant namely Rheofloc 5023 in combination with three flocculants including Rheofloc 5414, Genesys genefloc and AR floc 100 were tested at various dosages for the reduction of conductivity assimilated with ions in the RO retentate from coal power plant was investigated at 40 and $60^{\circ} \mathrm{C}$. The $A R$ floc 100 was determined to be the optimum flocculant required for the RO reject treatment. The optimum flocculant dosage resulted in $1 \mathrm{ppm}$ along with a Rheofloc 5023 coagulant dosage of 0.7 ppm.
\end{abstract}

Keywords-AR floc 100, RO retentate, flocculation, conductivity.

\section{INTRODUCTION}

Eskom generates the majority of South Africa's electricity and about half the electricity used in Africa.

Eskom is a large consumer of water from rivers and dams and account for approximately $1.5 \%$ of South Africa's total water consumption [1-7]. The freshwater undergoes extensive purification and treatment before it can enter the production process. It might be challenging to recycle wastewater from the RO retentate stream, because of the increase in the concentration of minerals in the water due to water evaporation.

Manuscript received October 03, 2018. This work was supported in part by the North West University and Eskom.

E Fosso-Kankeu is with the Water Pollution Monitoring and Remediation Initiatives Research Group at the school of Chemical and Minerals Engineering, North West university, South Africa.

L van Schalkwyk is with the Water Pollution Monitoring and Remediation Initiatives Research Group at the school of Chemical and Minerals Engineering, North West University, South Africa.

JC van der Linde is with the Water Pollution Monitoring and Remediation Initiatives Research Group at the school of Chemical and Minerals Engineering, North West University, South Africa.

G Gericke is with the Eskom research facility, Rosherville, South Africa.

F Waanders is with the Water Pollution Monitoring and Remediation Initiatives Research Group at the school of Chemical and Minerals Engineering, North West university, South Africa.
When the concentration of dissolved metal ions is too high, the ions become concentrated and exceed the solution solubility in the cooling water. These concentrated ions result in scale formation (calcium carbonate) on the surfaces. Anion concentrate influences the amount of scaling taking place in the system. Dissolved metal ions include calcium, magnesium, iron, and anions include carbonate, phosphate, silica and sulphate. The portion of cooling tower process water being flushed down the drain is referred to as cooling reverse osmosis (RO) retentate water Error! Reference source not found.. The RO retentate is simultaneously replaced with fresh water.

Coagulation-flocculation involves the addition of a flocculant (polymer) to form flocs with small, destabilised particles in the water [9-14]. These flocs are larger aggregates that can be separated from the water more easily. Coagulation is a chemical process that neutralizes the solution whereas flocculation is a physical process that destabilises the small particles inside the solution Error! Reference source not found.. Crystallisation is based on the limited solubility of a compound in a solvent at certain conditions. Crystalline solids will form when the conditions change to a state where the solubility is lower than the concentration of the compound in the solvent Error! Reference source not found.

For this project water samples were obtained from Grootvlei, one of Eskom's power stations situated close to Balfour, Mpumalanga. The characteristics that influence the tendency of corrosion and scaling taking place include the $\mathrm{pH}$, hardness (calcium), alkalinity, temperature and the total amount of dissolved solids in the water Error! Reference source not found.. The approach of this project is to treat water samples with different flocculants at difference dosages to determining the optimum treatment conditions for the RO retentate water at Eskom.

\section{Methodology}

\section{A. Characterisation of water samples}

The sampling trips to the power station plant were on the $23^{\text {rd }}$ of July, $13^{\text {th }}$ of August and $26^{\text {th }}$ of August. The water samples obtained from Eskom were characterised before and after the experimental treatment. Parameters considered during the characterization of water samples included turbidity, $\mathrm{pH}$, total hardness, conductivity and alkalinity. 
TABLE I: INITIAL WATER CHARACTERISTICS

\begin{tabular}{|l|l|l|l|l|}
\hline Parameter & Unit & 1 sample & $13-$ Aug & $26-$ Aug \\
\hline $\mathrm{pH}$ & - & 7.83 & 8.36 & 8.66 \\
\hline Conductivity & $\mathrm{mS}$ & 5.75 & 3.94 & 3.75 \\
\hline Turbidity & $\mathrm{NTU}$ & 2.56 & 1.66 & 0.81 \\
\hline Alkalinity & $\mathrm{mg} \mathrm{CaCO}_{3} / \mathrm{L}$ & 60 & 48 & 56 \\
\hline
\end{tabular}

\section{EXPERIMENTAL SETUP}

The jar test equipment consisted of six small scale agitators which were connected to a speed motor with variable speed options.

Just before the rapid mixing started the coagulant and flocculant were added to the water sample in each beaker. There were six different coagulant dosages, each dosage in a different beaker, and only one flocculant dosage was used per run. The Rheofloc 5023 coagulant dosages included, $0.2 \mathrm{ppm}, 0.5 \mathrm{ppm}$, $0.7 \mathrm{ppm}, 2 \mathrm{ppm}, 5 \mathrm{ppm}$ and $7 \mathrm{ppm}$. The flocculant dosages included, $0.5 \mathrm{ppm}$ and $1 \mathrm{ppm}$ for Rheofloc 5414, also $0.5 \mathrm{ppm}$ and $1 \mathrm{ppm}$ for Genesys genefloc and lastly, $1 \mathrm{ppm}$ and $7 \mathrm{ppm}$ for AR floc 100.

During rapid mixing, the interaction between the chemicals and the particles in solution was enhanced while during the slow mixing period the flocs were able to agglomerate and form precipitate Error! Reference source not found.

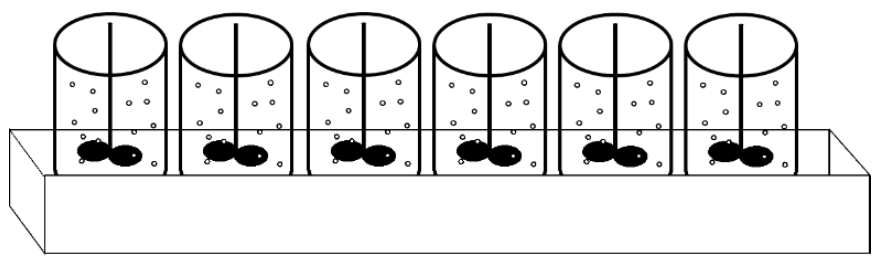

Fig 1: Jar test mixing equipment

\section{EXPERIMENTAL PROCEDURE}

\section{A. $p H$, conductivity and turbidity}

The $\mathrm{pH}$ of each sample was determined by using a HANNA HI $8424 \mathrm{pH}$ meter. The conductivity meter used was the Lovibond SensoDirect 150 water quality meter and the turbidity was measured using a HACH 2100Q portable turbidity meter.

\section{B. Alkalinity}

The endpoint titration method was used to determine the alkalinity of the water. This method is explained in a book called the Standard Methods for the Examination of Water and Wastewater Error! Reference source not found.

- $\quad$ Standard solution was prepared by dissolving $1.0075 \mathrm{~g}$ of $98 \% \mathrm{H}_{2} \mathrm{SO}_{4}$ in $1 \mathrm{~L}$ demineralized water.

- $50 \mathrm{~mL}$ of the treated water was used for these titrations

- A few drops of Phenolphthalein were added to the sample to obtain a pink colour.

- $\mathrm{H}_{2} \mathrm{SO}_{4}$ was added with a burette until the solution colour turned from pink to colourless.

- Another indicator namely Bromocresol green was added at this stage to determine the volume needed to obtain a $\mathrm{pH}$ of 4.5 at which the indicator changes the colour from blue to light green.

\section{ICP-OES analysis}

The concentration of each metal in the treated $\mathrm{RO}$ retentate water was obtained by using an Inductively coupled plasma optical emission spectrometry (Agilent Technologies 700 Series ICP-OES. Since the total hardness of these samples are relatively high, the samples were diluted (x100). The total hardness was calculated with Eq. 1: Error! Reference source not found.

$\mathrm{CaCO}_{3}(\mathrm{mg} / \mathrm{L})=2.497(\mathrm{Ca}, \mathrm{mg} / \mathrm{L})+4.118(\mathrm{Mg}, \mathrm{mg} / \mathrm{L})$

\section{Chemical composition}

The dried flocs were obtained using a Hettich Zentrifugen ROTOFIX 32 A centrifuge. This was done by decanting the purified $\mathrm{RO}$ retentate water, pouring the remaining flocs into a centrifuge tube and using the centrifuge to separate the liquid from the flocs completely. The flocs were dried for 24 hours at $50^{\circ} \mathrm{C}$ in an incubator. The dried flocs were sent for SEM-EDS analysis to determine the morphology and the elemental composition of the flocs.

\section{E. Settling velocity}

A cone was used to evaluate the settling velocity of the flocs that were formed during the jar test. The settling rate was determined by observing the changes of volume taking place in the cone over time. The cone was marked from 1 to $10 \mathrm{~mL}$ and the time was recorded when the flocs reached each volume mark. The volume over time curve was obtained which allowed to determine the settling rate. The settling test was done by following the same procedure as the optimization jar tests and performing the cone test directly after slow mixing.

\section{F. Stability test}

The floc stability was determined by observing the change in the treated water directly after a jar test has been done. A jar test was done with the best coagulant and flocculant dosage but this time at $60^{\circ} \mathrm{C}$ at the same speed and time intervals. After the 30 minutes settling period, the flocs were disturbed through further rapid mixing for 30 seconds and then the turbidity was determined with the turbidimeter every 50 seconds to obtain a graph of turbidity versus time. This was use to determine the stability of the flocs.

\section{RESUlTS AND DISCUSSION}

\section{A. Optimization}

\section{1) $p H$, conductivity and turbidity}

a) Rheofloc 5414 - Flocculant 1

Firstly, the Rheofloc 5414 flocculant was used to do the jar tests. The conductivity removal results are shown in the graph below, Fig 2 . The conductivity was not successfully removed with Rheofloc 5414. For the $1 \mathrm{ppm}$ flocculant dosage, the conductivity removal was less than zero percent meaning the conductivity increased with an average of $2 \%$. For the $0.5 \mathrm{ppm}$ flocculant dosage, the conductivity was removed successfully for the coagulant dosages; $0.2 \mathrm{ppm}, 0.5 \mathrm{ppm}, 0.7 \mathrm{ppm}$ and 2 ppm. For both the coagulant and flocculant dosage of $0.5 \mathrm{ppm}$, 
the best results for the removal of conductivity was obtained reducing the conductivity of the water by $10 \%$.

The turbidity of these water samples was initially very low and therefore the experiments did not have a significant effect on the turbidity removal. The turbidity removal for the dosage 7 ppm coagulant and $0.5 \mathrm{ppm}$ flocculant gave the optimum result.

b) Genesys Genefloc - Flocculant 2

The conductivity results for Genesys Genefloc are shown below in Fig 3. The conductivity removal results of the Genefloc dosage $0.5 \mathrm{ppm}$ was more stable than that of the Rheofloc 5414 but also not sufficient in the removal of conductivity. The $1 \mathrm{ppm}$ flocculant dosage shows two peaks in the graph at $0.5 \mathrm{ppm}$ and $7 \mathrm{ppm}$. The optimum conductivity removal with Genefloc was $35 \%$ and $36 \%$.

For Genesys Genefloc, the turbidity was successfully removed with the $1 \mathrm{ppm}$ flocculant dosage at coagulant dosages greater than $0.2 \mathrm{ppm}$. The optimum turbidity removal was $26 \%$ resulting from a coagulant dosage of $5 \mathrm{ppm}$ and $1 \mathrm{ppm}$ flocculant dosage.
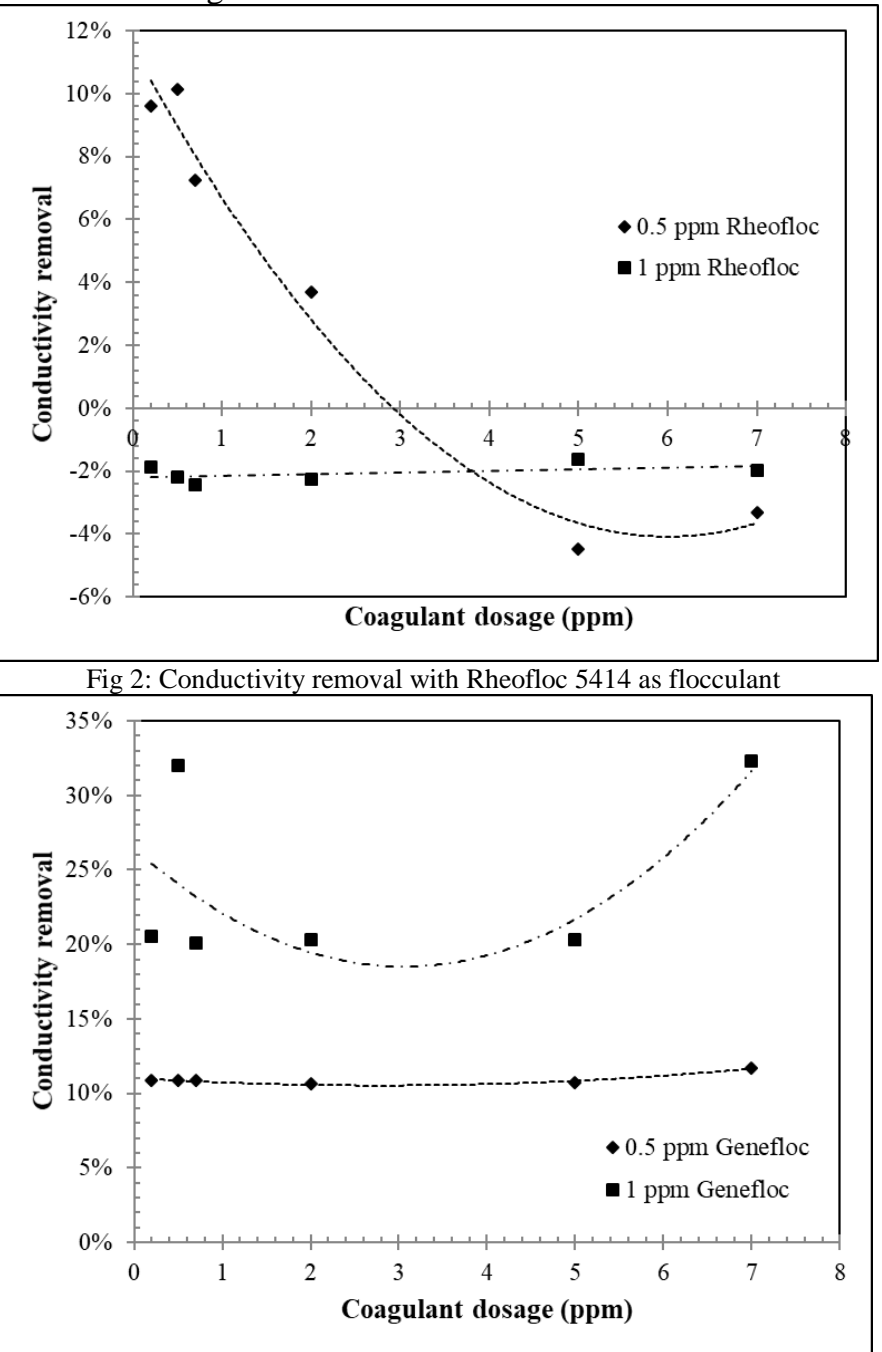

Fig 3: Conductivity removal with Genesys Genefloc

c) AR floc 100 - Flocculant 3

The conductivity removal results are shown in Fig 4 with AR floc 100 as flocculant. The conductivity removal results average at a value of $17 \%$ for $1 \mathrm{ppm}$ AR floc 100 and $24.5 \%$ for $7 \mathrm{ppm}$ AR floc 100. The optimum conductivity removal at $7 \mathrm{ppm}$ flocculant is $25 \%$ at a coagulant dosage of $2 \mathrm{ppm}$. Since $7 \mathrm{ppm}$ is much higher than $1 \mathrm{ppm}$ flocculant, it might be considered to use the $1 \mathrm{ppm}$ flocculant dosage for economic reason. This aspect will also be taken into consideration later in this study.

The turbidity removal with AR floc 100 was unsuccessful. The turbidity increased for both flocculant dosages.

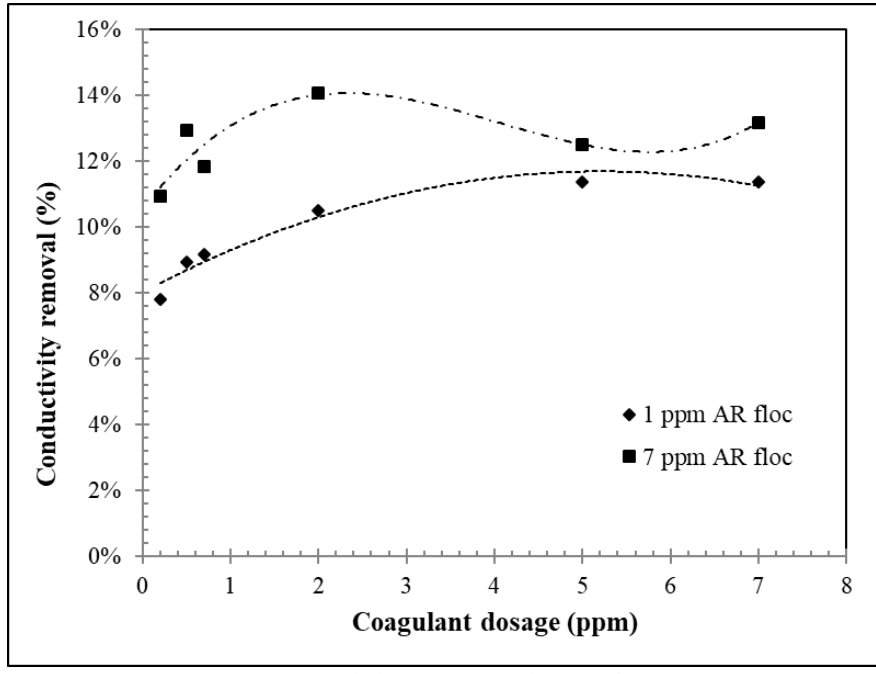

Fig 4: Conductivity removal with AR floc 100

\section{2) Alkalinity}

The alkalinity removal overall was very successful with an average of 53\% for all three flocculants. This shows that each flocculant is sufficient, in fact, the optimum conditions were determined prior to this study. These experiments were carried out at $40{ }^{\circ} \mathrm{C}$ and after the optimum dosage were determined the temperature was changed to $60{ }^{\circ} \mathrm{C}$ to assess the effect of higher temperature on the performance of the coagulant and flocculants. The alkalinity removal results showed the same trend for the three flocculants. A spike in the alkalinity removal was observed around the coagulant dosages $0.5 \mathrm{ppm}$ and 0.7 ppm. A significant reduction in the alkalinity removal was observed at a coagulant dosage greater than $0.7 \mathrm{ppm}$ and afterwards a gradual increase was observed. This section consists of three figures displaying the trend of the results and the optimum conditions thereof are discussed.

The alkalinity removal with Rheofloc 5414 as flocculant averaged at $55 \%$ at $0.5 \mathrm{ppm}$ flocculant and $54 \%$ at $1 \mathrm{ppm}$ flocculant. In Fig 5 it is shown that the best Rheofloc 5414 dosage is $0.5 \mathrm{ppm}$ with a coagulant dosage of $0.7 \mathrm{ppm}$. This dosage resulted in an alkalinity removal of 59\%.

The results obtained with Genesys genefloc is shown in Fig 6. The best flocculant dosage was $1 \mathrm{ppm}$ at an optimum coagulant dosage of $7 \mathrm{ppm}$. This resulted in an alkalinity removal of 57\%. The 5 ppm coagulant dosage reduced the alkalinity by $53 \%$ which is only $4 \%$ lower, while using less coagulant, making it cost effective.

The alkalinity removal with AR floc 100 as flocculant is shown in Fig 7. The best alkalinity removal result obtained was $62 \%$ at $7 \mathrm{ppm}$ AR floc 100 and $0.5 \mathrm{ppm}$ coagulant dosage. The alkalinity removal with AR floc 100 was $4 \%$ better than with Rheofloc 5414 and Genesys genefloc as flocculants. Since the cost of the chemicals are considered it is better to choose the dosage of $1 \mathrm{ppm}$ AR floc 100 and $0.7 \mathrm{ppm}$ coagulant with a 
removal of $57 \%$. The alkalinity removal is thus only $5 \%$ less and the flocculant expenses will be much cheaper than that of $7 \mathrm{ppm}$. AR floc 100 could therefore be considered as the optimum flocculant to remove the alkalinity of RO retentate water at Eskom.

The optimum flocculant and coagulant dosage resulted in AR floc 100 with a dosage of $1 \mathrm{ppm}$ and a coagulant dosage of 0.7 ppm. This was the best result considering the expenses and the efficiency. The best flocculant was also tested with the optimum dosage at $60^{\circ} \mathrm{C}$. At a $\mathrm{pH}$ of 9.03 the conductivity removal was successful reducing the conductivity with $25 \%$, although the turbidity of the water increased by $34 \%$ at these conditions. The alkalinity removal resulted in $51 \%$ which was $7 \%$ less than the removal at $40^{\circ} \mathrm{C}$.
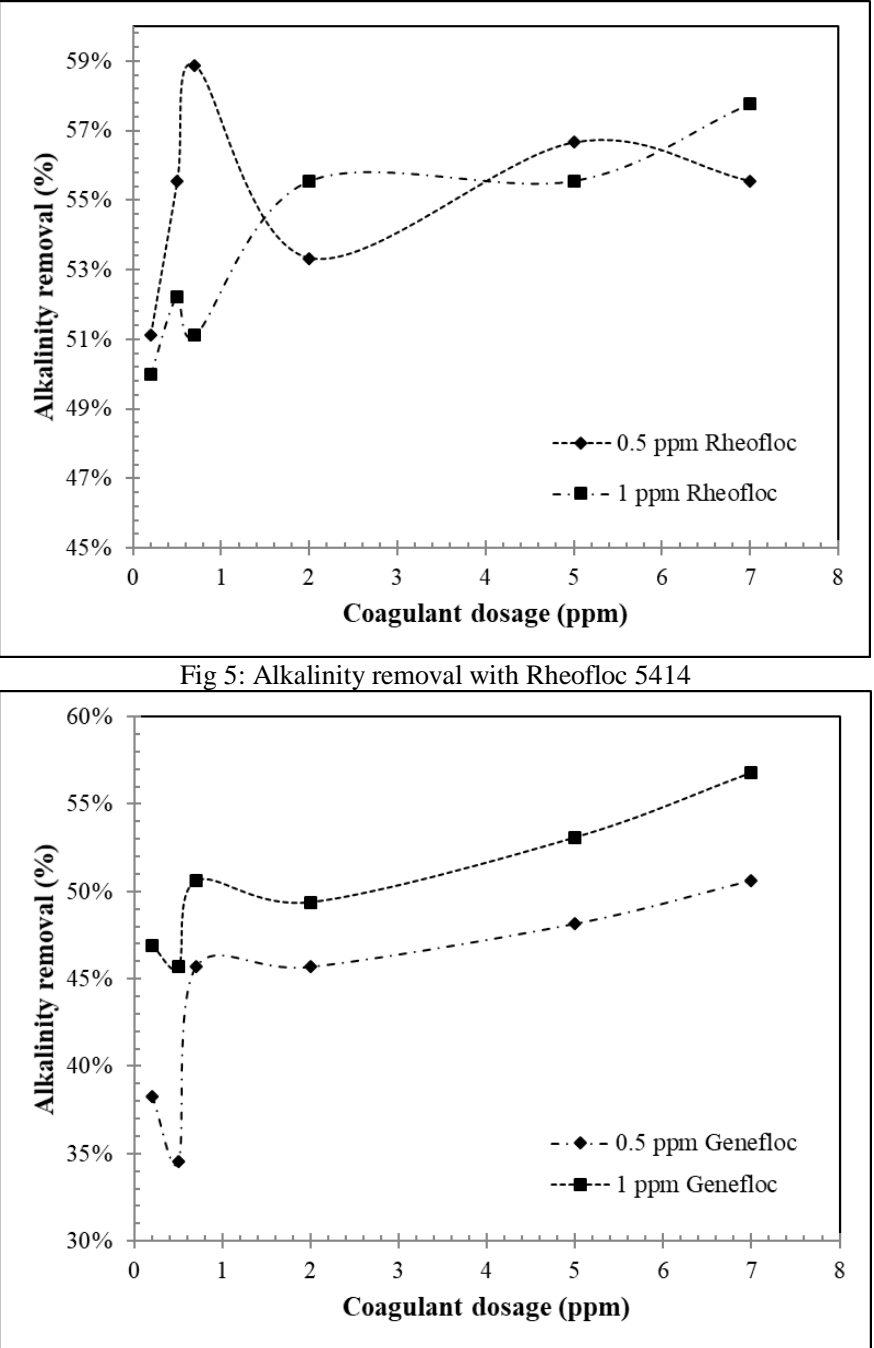

Fig 6: Alkalinity removal with Genesys genefloc

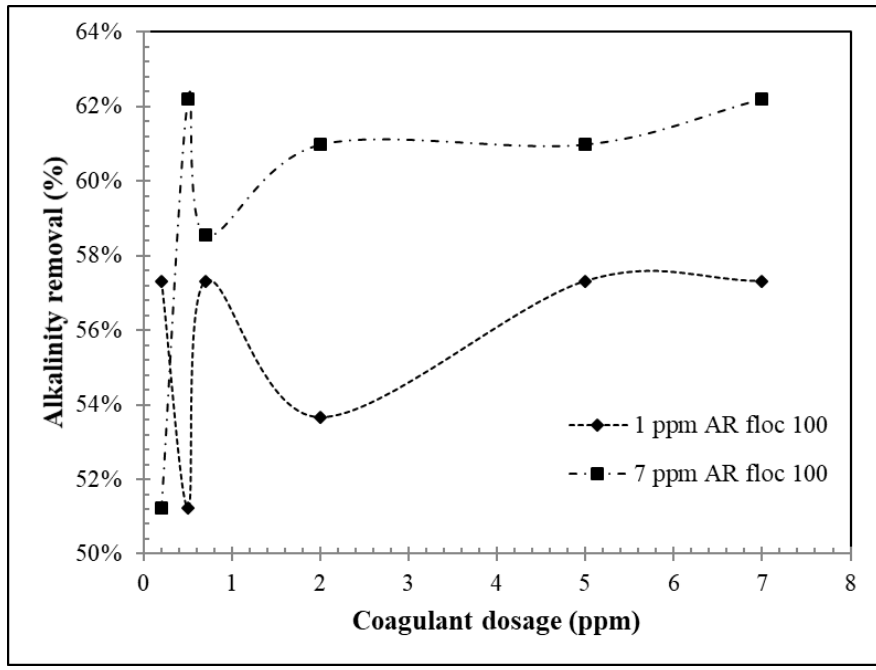

Fig 7: Alkalinity removal with AR floc 100

\section{B. Settling velocity}

The settling velocity of the flocs at $40{ }^{\circ} \mathrm{C}$ and $60^{\circ} \mathrm{C}$ is summarized in Error! Reference source not found.. The settling velocity decrease with time due to the density difference of the flocs. Initially the flocs have a high density which leads to a high settling rate. As time progresses the settling velocity reduces due to the lower density of the remaining flocs. These flocs that remain in solution, will take more time to settle. The $10 \mathrm{~mL}$ floc bed was obtained within 109 seconds at $40^{\circ} \mathrm{C}$ and in 114 seconds at $60^{\circ} \mathrm{C}$.

It is recommended to proceed with $40^{\circ} \mathrm{C}$ since it would be less costly to run the system at a lower temperature.

TABLE II: SETTLING VELOCITY AT 40OC AND 60OC

\begin{tabular}{|c|c|c|c|}
\hline Time (s) & $\begin{array}{l}\text { Settling } \\
\text { velocity }\end{array}$ & Time (s) & $\begin{array}{l}\text { Settling } \\
\text { velocity }\end{array}$ \\
\hline \multicolumn{3}{|c|}{$40^{\circ} \mathrm{C}$} & \multicolumn{2}{|c|}{$60^{\circ} \mathrm{C}$} \\
\hline 40 & 0.321 & 30 & 0.265 \\
\hline 50 & 0.257 & 40 & 0.199 \\
\hline 60 & 0.214 & 50 & 0.159 \\
\hline 70 & 0.184 & 60 & 0.133 \\
\hline 80 & 0.161 & 70 & 0.114 \\
\hline 90 & 0.143 & 80 & 0.100 \\
\hline 100 & 0.128 & 90 & 0.088 \\
\hline
\end{tabular}

\section{Floc stability}

\section{1) Slow mixing regime}

In the slow mixing regime, the flocs were mixed at $100 \mathrm{rpm}$ before the stability test was done. The average slope for the stability test at $40^{\circ} \mathrm{C}$ was -5.37 . The same calculation was performed with the stability test trendline at $60^{\circ} \mathrm{C}$ and a slope of -13.13 was obtained. The rapid decrease in turbidity indicate that the floc stability is much higher at $60^{\circ} \mathrm{C}$ than at $40^{\circ} \mathrm{C}$.

\section{2) Rapid mixing regime}

A stability test was also done at $200 \mathrm{rpm}$ for both $40^{\circ} \mathrm{C}$ and $60^{\circ} \mathrm{C}$. For the stability test at $40^{\circ} \mathrm{C}$, the slope of the average trendline was -5.02 . For the stability test at $60^{\circ} \mathrm{C}$, a slope of -18.40 was determined. Since the turbidity decrease faster at $60^{\circ} \mathrm{C}$, it is shown that the flocs are more stable than at $40^{\circ} \mathrm{C}$. 
Finally, it can be concluded the best floc stability will be obtained at $60^{\circ} \mathrm{C}$.

\section{ICP-OES analysis}

The main objective of this project was to reduce the alkalinity and total hardness of the RO retentate water at Eskom power station. The results of the ICP-OES analysis are summarized in Table III and IV. This indicates the total hardness removal efficiency of the treatment with AR floc 100. The best calcium and magnesium removal efficiency according to the ICP-OES analysis is $46 \%$ for a flocculant dosage of $1 \mathrm{ppm}$ at $60^{\circ} \mathrm{C}$. The results between 1 and $7 \mathrm{ppm}$ did not differ significantly as seen in the tables below.

TABLE III: ICP-OES RESULTS OF RO AT 40OC (TOTAL HARDNESS)
\begin{tabular}{|c|c|c|}
\hline Treatment & $\begin{array}{c}\text { Total } \\
\text { hardness } \\
\left(\mathrm{CaCO}_{3}\right)\end{array}$ & $\begin{array}{c}\text { Content } \\
\text { reduction }\end{array}$ \\
\hline & $(\mathrm{mg} / \mathrm{l})$ & $(\%)$ \\
\hline Untreated RO & 224.25 & - \\
\hline $1 \mathrm{ppm}$ & 160.57 & $42 \%$ \\
\hline $7 \mathrm{ppm}$ & 181.42 & $45 \%$ \\
\hline
\end{tabular}

TABLE IV: ICP-OES RESULTS OF RO AT 60OC (TOTAL HARDNESS)

\begin{tabular}{|c|c|c|}
\hline Treatment & $\begin{array}{c}\text { Total } \\
\text { hardness } \\
\left(\mathrm{CaCO}_{3}\right)\end{array}$ & $\begin{array}{c}\text { Content } \\
\text { reduction }\end{array}$ \\
\hline & $(\mathrm{mg} / \mathrm{l})$ & $(\%)$ \\
\hline Untreated RO & 224.25 & - \\
\hline $1 \mathrm{ppm}$ & 187.43 & 46 \\
\hline $7 \mathrm{ppm}$ & 182.23 & 45 \\
\hline
\end{tabular}

\section{E. SEM EDS analysis}

The chemical composition analysis was performed for the RO retentate treated at $40^{\circ} \mathrm{C}$ and $60^{\circ} \mathrm{C}$. It can be observed that the flocs formed at $60^{\circ} \mathrm{C}$ are smaller in size compared to the flocs formed at $40^{\circ} \mathrm{C}$; this is due to increased dehydration taking place at a higher temperature resulting in more rigid or stable but less heavier flocs. The crystallization was advanced at $60^{\circ} \mathrm{C}$ and resulted in the formation of crystals and nanorods as observed in Fig 8 and Fig 9. The energy dispersive spectra of the respective images show the entrapment of elements such as $\mathrm{Ca}, \mathrm{Mg}, \mathrm{Yb}$, $\mathrm{Na}, \mathrm{Si}, \mathrm{K}, \mathrm{Al}, \mathrm{Co}, \mathrm{Br}$ and $\mathrm{Cu}$ in the flocs which can contribute in the reduction of scale formation.

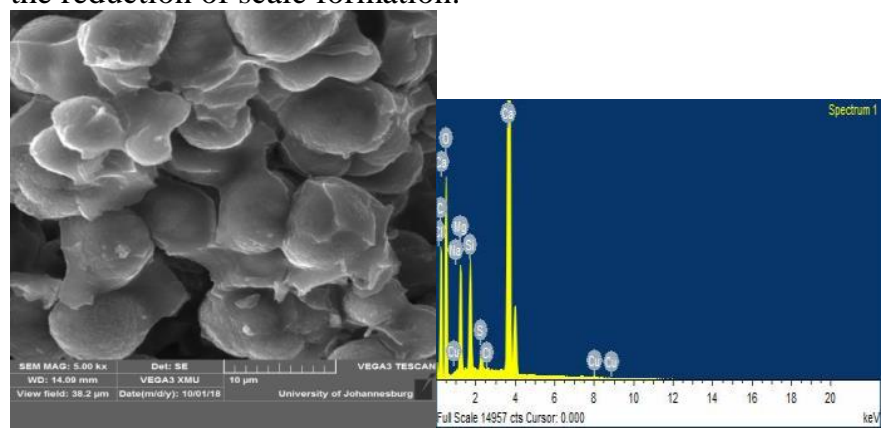

Fig 8: SEM image and EDS spectrum for RO sample treated at $40^{\circ} \mathrm{C}$

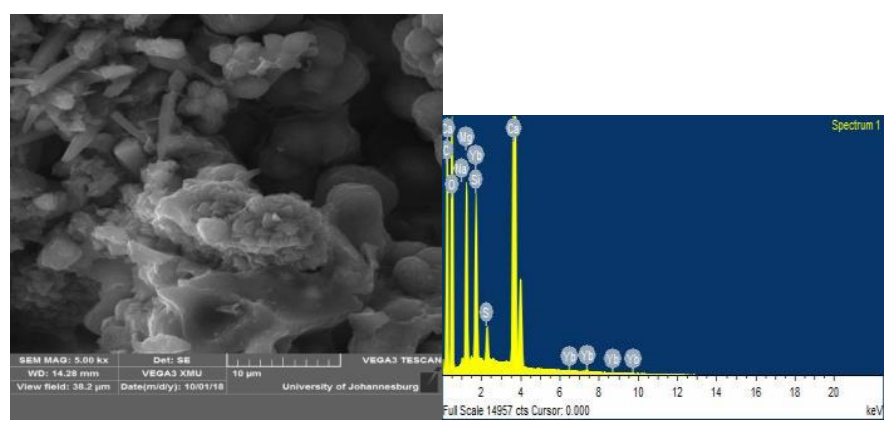

Fig 9: SEM image and EDS spectrum for RO sample treated at $60^{\circ} \mathrm{C}$

\section{CONCLUSION AND RECOMMENDATIONS}

In conclusion, the coagulation-flocculation treatment method was successful in removing total hardness and alkalinity from the RO retentate water at Eskom. The characteristics of the untreated $\mathrm{RO}$ retentate showed a $\mathrm{pH}$ ranging between 7.8 and 8.7 , an average turbidity of 4.48 NTU and a conductivity of 4.48 $\mathrm{mS}$.

The AR floc 100 was identified as the best flocculant suitable for the RO reject treatment. The optimum flocculant dosage was $1 \mathrm{ppm}$ combined with a Rheofloc 5023 coagulant dosage of 0.7 $\mathrm{ppm}$. The settling velocity of the flocs formed during coagulation-flocculation was determined along with the stability thereof. The settling velocity results at $40^{\circ} \mathrm{C}$ and $60^{\circ} \mathrm{C}$ were found to be very similar. A floc bed of $10 \mathrm{~mL}$ was obtained within 109 seconds at $40^{\circ} \mathrm{C}$ and 114 seconds at $60^{\circ} \mathrm{C}$. The stability of the flocs was higher at $60^{\circ} \mathrm{C}$ compared to $40^{\circ} \mathrm{C}$.

\section{REFERENCES}

[1] E. Fosso-Kankeu, J. Redelinghuys, F. Waanders, D. Rogers, D. Bruinsma, G. Gericke, Determination of water evaporation rate in an assembled bench scale MED and impact of anti-scaling agents on the morphology of scale. International Conference on Advances in Science, Engineering, Technology and Natural Resources (ICASETNR-16) Nov. 24-25, 2016, Parys - South Africa. ISBN: 978-93-84468-79-8. 2016.

[2] E. Fosso-Kankeu, F. Waanders, D. Van Niekerk, D. Rogers, G. Gericke, Treatment of raw and processed waters from coal power plant using PACl supplemented with cationic organic polymer and bentonite. International Conference on Advances in Science, Engineering, Technology and Natural Resources (ICASETNR-16) Nov. 24-25, 2016, Parys - South Africa. ISBN: 978-93-84468-79-8. 2016.

[3] E. Fosso-Kankeu, F. Waanders, R. Swiegers, I.O. Ntwampe, D. Rogers, G. Gericke, Impact of the physico-chemical properties of water on the flocculation performance of lime, clay and other polymers. International Conference on Advances in Science, Engineering, Technology and Natural Resources (ICASETNR-16) Nov. 24-25, 2016, Parys - South Africa. ISBN: 978-93-84468-79-8. 2016.

[4] E. Fosso-Kankeu, F.B. Waanders, G. Gericke, N. Lemmer, L.M. Dreyer and $\mathrm{J}$. van der Linde, Investigation of the potential of monomeric and polymeric coagulants in the treatment of raw water used at a coal-fired power station. $9^{\text {th }}$ Int'l Conference on Advances in Science, Engineering, Technology \& Waste Management (ASETWM-17). 27-28 November 2017, Parys, South Africa. Editors: F. Waanders, E. Fosso-Kankeu, B. Topcuoglu, M. Plaisent, Y. Thaweesak. ISBN: 978-81-934174-6-1. Pp. 44-48. 2017.

[5] J.C. van der Linde, E. Fosso-Kankeu, G. Gericke, N. Lemmer, and F. Waanders, Removal of Total Hardness and Alkalinity from RO - reject water. $9^{\text {th }}$ Int'l Conference on Advances in Science, Engineering, Technology \& Waste Management (ASETWM-17). 27-28 November 2017, Parys, South Africa. Editors: F. Waanders, E. Fosso-Kankeu, B. 
Topcuoglu, M. Plaisent, Y. Thaweesak. ISBN: 978-81-934174-6-1. Pp. 147-151. 2017.

[6] E. Fosso-Kankeu, C.E. Brider, J. Redelinghuys, G. Gericke, N. Lemmer, F. Waanders, Determination of suitable anti-scaling agent to inhibit scale formation of water processed in coal power plant system. $9^{\text {th }}$ Int'l Conference on Advances in Science, Engineering, Technology \& Waste Management (ASETWM-17). 27-28 November 2017, Parys, South Africa. Editors: F. Waanders, E. Fosso-Kankeu, B. Topcuoglu, M. Plaisent, Y. Thaweesak. ISBN: 978-81-934174-6-1. Pp. 30-36. 2017.

[7] J. Redelinghuys, E. Fosso-Kankeu, F. Waanders, D. Rogers, G. Gericke, Scaling conditions inside improved bench-scale single effect vacuum evaporator. $9^{\text {th }}$ Int'l Conference on Advances in Science, Engineering, Technology \& Waste Management (ASETWM-17). 27-28 November 2017, Parys, South Africa. Editors: F. Waanders, E. Fosso-Kankeu, B. Topcuoglu, M. Plaisent, Y. Thaweesak. ISBN: 978-81-934174-6-1. Pp. 169-174. 2017.

[8] B.W. Everett, B.L. Herbert, F.L. Thomas, Auxiliary Steam-Plant Equipment. Steam Plant Operation, Ninth Edition (9.): McGraw Hill Professional, Access Engineering. Fang, G. 2007. Evaluation and Performance of a Tannin-based Polymer as a Coagulant in Water Treatment, 2012.

[9] E. Fosso-Kankeu, F. Waanders, Metal Ions Adsorption Affinity of Clay Materials from the North West Province of South Africa. An Interdisciplinary Response to Mine Water Challenges. International Mine Water Conference, August 2014 Xuzhou China. Editors, Sui, Sun \& Wang (Eds). 2014 China University of Mining andTechnology Press, Xuzhou, ISBN: 978-7-5646-2437-8. Pp374-378. 2014.

[10] I.O. Ntwampe, F.B. Waanders, E. Fosso-Kankeu, J.R. Bunt, Reaction dynamics of iron and aluminium salts dosage in AMD using shaking as an alternative technique in the destabilization-hydrolysis process. International Scientific Research Journal. Vol. 1, no. 8, pp. 5-23, 2015.

[11] E. Fosso-Kankeu; O. Ntwampe, F. Waanders, and A. Webster, The Performance of Polyaluminium Chloride and Bentonite clay Coagulant in the Removal of Cationic and Anionic Dyes. ${ }^{\text {th }}$ International Conference on Latest Trends in Engineering and Technology (ICLTET' 2015), November 26-27, 2015 Irene, Pretoria (South Africa). Editors: E. Muzenda and T Yingthawornsuk. ISBN: 978-93-84422-58-5. 2015.

[12] E. Fosso-Kankeu, H. Mittal, F. Waanders, I.O. Ntwampe, S.S. Ray, Preparation and characterization of gum karaya hydrogel nanocomposite flocculant for metal ions removal from mine effluents. International Journal of Environmental Science and Technology. Vol. 13, pp. 711-724, 2016 https://doi.org/10.1007/s13762-015-0915-x

[13] E. Fosso-Kankeu, A. Webster, I.O. Ntwampe, F.B. Waanders, Coagulation/flocculation potential of polyaluminium chloride and bentonite clay tested in the removal of methyl red and crystal violet. Arabian Journal for Science and Engineering. DOI 10.1007/s13369-016-2244-x. 2016.

[14] E. Fosso-Kankeu, F. Waanders, A.F. Mulaba-Bafubiandi, A.K. Mishra, Flocculation performances of polymers and nanomaterials for the treatment of industrial wastewaters. In A.K. Mishra (ed). 2016. Smart Materials for Waste Water Applications. Wiley Scrivener. ISBN: 9781119041184. Pp 213 - 235, 2016.

[15] A.C. Robert, Suspended solids treatment. Standard Handbook of Environmental Engineering, Second Edition: McGraw Hill Professional, Access Engineering, 1999.

[16] W.G. Don, \& H.P. Robert, Crystallization from the melts. Perry's Chemical Engineers' Handbook (8.): McGraw Hill Professional, Access Engineering. Eskom. 2011. Water managemnet. http://financialresults.co.za/2011/eskom_ar2011/downloads/eskom-ar20 11.pdf Date of access: 24 July 2018, 2008.

[17] F. Michael, Water treatment and purification. Facility Piping Systems Handbook: For Industrial, Commercial, and Healthcare Facilities, Third Edition (3.): McGraw Hill Professional, Access Engineering, 2010.

[18] E.W. Rice, R.B. Baird, A.D. Eaton, L.S. Clesceri, Standard Methods for the Examination of Water and Wastewater. 22nd Edition. Washington DC: American Public Health Association, American Water Works Association and Water Environment Federation, 2012.

[19] A.D. Eaton, L.S. Clesceri, A.E. Greenberg, Standard methods for the examination of water and wastewater. 19th Edition. Washington, DC 20005: American public health association, American water works association, Water environment federation, 1995. 